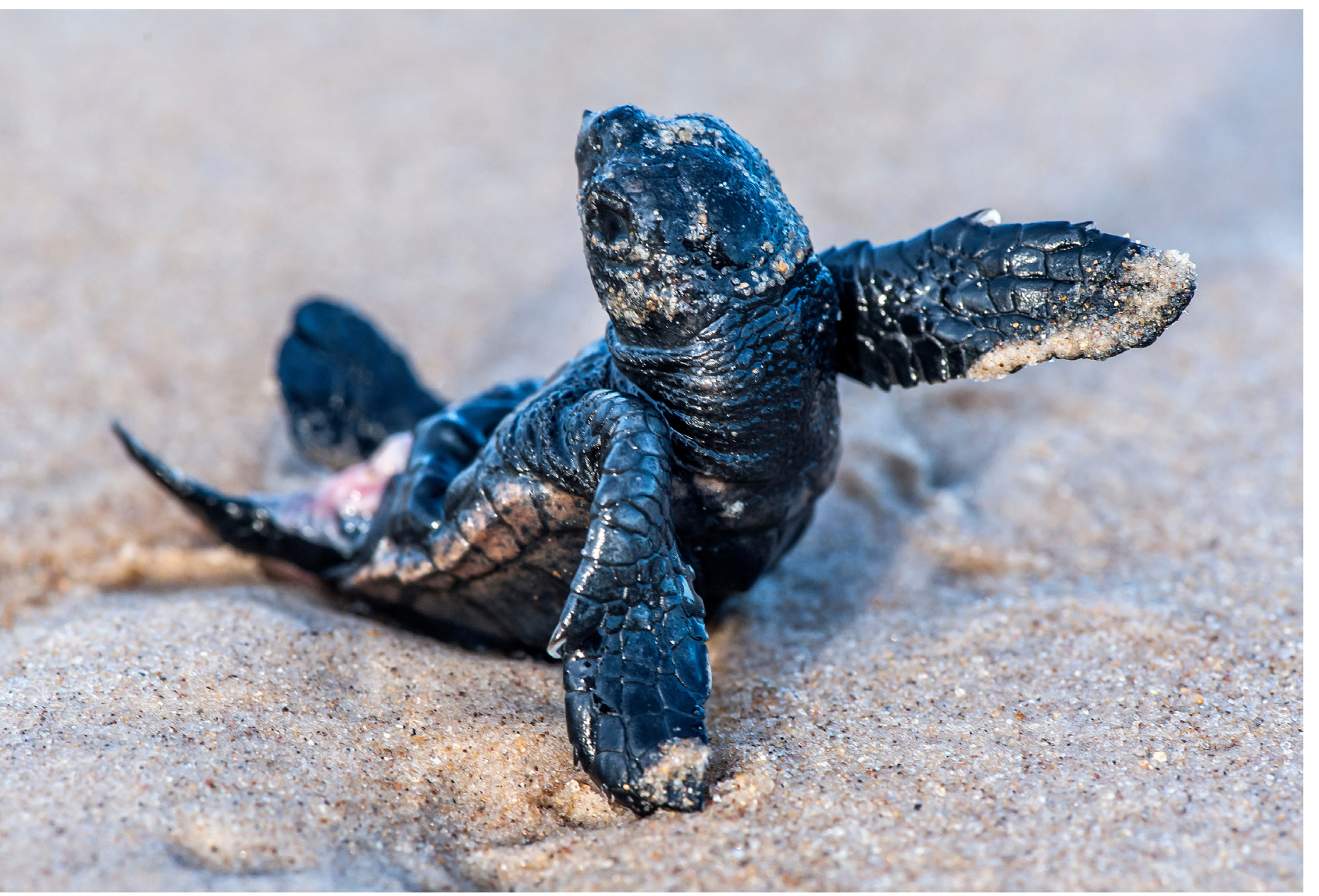




\section{Ações para o Ensino e Aprendizagem facilitados em Botânica nas Escolas do Ensino Básico}

Actions for Teaching and Learning Facilitated in Botany in Schools

\section{Resumo}

A temática botânica vem sendo pouco tratada nas escolas; dentre os motivos estão terminologias e metodologias de ensino, Raphael de Souza Peçanha geralmente focadas no livro didático. Nesse contexto, herbário e laboratórios tornam-se instrumentos didáticos eficientes, possibilitando aos alunos conhecimento de uma realidade na qual eles não estão inseridos. Objetivou-se mostrar alternativas viáveis para ensinar e aprender botânica dentro de Ciências/ Biologia na educação básica, refletindo na formação inicial dos estudantes de forma que os coloquem como agentes ativos na construção do conhecimento. O público-alvo foram alunos e professores das escolas de Carangola e região. Escolheram-se temas e metodologias diferenciadas para montagem de aulas dinâmicas, com intuito de ensinar botânica de maneira diferenciada. Foram recebidos 701 alunos de nove escolas. Os resultados indicaram que o trabalho proporcionou melhor compreensão do conteúdo botânico e despertou consciência ambiental nos alunos. Além disso, o projeto mostrou o quanto o herbário HUEMG é importante para a região e propiciou iniciação à docência aos alunos graduandos em Biologia.

Palavras-Chave: Ensino; Botânica; Herbário; Iniciação à Docência; Educação Ambiental. 
Abstract

The botanical theme has been little noticed in schools, among the reasons are terminologies and teaching methodologies, usually focused on the textbook. In this context, herbarium and laboratories become efficient didactic instruments, enabling students to know a reality that they are not inserted. The objective was to show viable alternatives to teach and to learn botany within Science / Biology in basic education, reflecting on the initial formation of students and placing them as active agents in the construction of knowledge. The target were students and teachers of the schools of Carangola and region. Different themes and methodologies were chosen for the assembly of the dynamic classes, in order to teach botany in a different way. 701 students from nine schools were received. The work provided a better understanding of botanical content and awakened environmental awareness in students. In addition, it showed how much the HUEMG herbarium is important for the region and provided initiation to teaching to students graduating in Biology.

Key words: Education; Botany; Herbarium; Introduction to Teaching; Environmental Education. 


\section{INTRODUÇÃO}

A Botânica pode ser descrita, de uma maneira simples, como "o ramo da biologia que trata da vida das plantas" e é uma disciplina relacionada ao cotidiano das pessoas, por abordar uma temática extremamente acessível, partindo-se da ideia de que as plantas estão em todos os lugares. Além disso, pode ser caracterizada pelo interesse em aspectos morfológicos, fisiológicos, genéticos de um ser vivo que é basicamente pluricelular e realizador da fotossíntese (SANTOS, 2006). 0 estudo do conteúdo de botânica fornece um importante entendimento da essência de toda a vida na Terra, desde a manutenção da vida até ao total equilíbrio do planeta.

No entanto, o conteúdo botânico se faz pouco notório nos ensinos fundamental e médio nas escolas, apesar de ser uma disciplina constitucionalizada dentro da biologia, considerada uma área interdisciplinar que tem como objetivo de estudos contribuir com outras áreas da biologia (SANTOS, 2006). A falta de interesse dos alunos pode ser apontada como um dos motivos, provavelmente pela carência de atrativos didáticos e pedagógicos e por conter muitos termos específicos. Outra razão pode ser explicada pelo fato de não haver interação entre o homem e os seres estáticos como as plantas (MENEZES et al., 2009).

Esta problemática tem como consequência a defasagem de conhecimento do conteúdo por parte dos alunos. Este fato pode estar relacionado com as metodologias aplicadas, em que na maioria das vezes são ministradas aulas com excesso de conteúdos e baseadas somente nos livros didáticos e teóricos (ROCKENBACH et al., 2012).

Em vista disso, novas abordagens são necessárias para que o aluno tenha um contato maior com os vegetais, por meio de aulas práticas ou de ações e aulas dinâmicas, como oficinas em campo, o uso de laboratórios e de recursos tecnológicos por exemplo. Essas ações promovem a qualificação do processo de aprendizagem, visando acrescentar os conhecimentos sobre a flora brasileira e as suas diversificações (ARAÚJO \& MIGUEL, 2013). Além do que, as aulas experimentais podem despertar a motivação e o interesse dos alunos pelo saber, facilitar a compreensão de fenômenos naturais e de concepções científicas, por exemplo, no campo da medicina e da farmacologia, dentre outras (POSSOBOM, 2002).

Nesse contexto, considerando as diversas problemáticas que os professores enfrentam para ministrar o conteúdo, as visitas técnicas a coleções biológicas, como em um herbário, concomitante às aulas práticas, apresentam-se como grande fonte de conhecimento e contribuem substancialmente para a aprendizagem dos alunos (PESSIN \& NASCIMENTO, 2010). Isto porque os Herbários, enquanto coleções botânicas, compostas por espécies de plantas conservadas e organizadas de maneira sistemática, provenientes de diversos tipos de ecossistemas, podem servir como registro referencial sobre o tipo de vegetação e a composição florística de determinada região (MACHADO \& BARBOSA, 2010). Tal coleção é considerada como fonte de grande formação de conhecimentos, nos ramos de pesquisa e extensão (ARAUJO \& MIGUEL, 2013). Junto às demais categorias de coleções científicas, os herbários compõem os espaços institucionalizados não-formais que 
podem ser utilizados para a prática de conscientização e educação ambiental de alunos de diversos níveis de ensino (Queiroz et al., 2011). Além disso, sobre o ponto de vista didático, um herbário é também um excelente instrumento educacional, pois proporciona aos professores recursos que irão permitir adequações dentro de suas necessidades didáticas (NUNES \& ALVES, 2016). A partir dessas considerações, buscou-se como objetivo desse trabalho apresentar alternativas viáveis para ensinar e aprender botânica, dentro do conteúdo de Ciências/Biologia na educação básica, por entender que essas atividades se refletem na formação inicial dos estudantes e os colocam como agentes ativos na construção do conhecimento.

\section{MATERIAL E MÉTODOS}

O projeto foi realizado durante o ano letivo de 2016. Inicialmente, passou-se ao agendamento prévio das aulas teóricas e práticas na Universidade do Estado de Minas Gerais, para visitas técnicas ao Centro de Estudos Ecológicos e da Biodiversidade (CEBIO), que incluem o herbário da Universidade do Estado de Minas Gerais (HUEMG), laboratórios e salas de multimídias da UEMG e UAITEC, com sede na UEMG-Carangola.

Os professores de Ciências/Biologia das escolas do Município de Carangola-MG e região foram contatados, para se conhecer as metodologias de ensino utilizadas por eles em sala de aula e o conteúdo das ementas. Foram contemplados professores e alunos dos níveis fundamental I e II, ensino médio e educação em tempo integral, além de alunos da APAE - Associação de Pais e Amigos dos Excepcionais de Carangola (Tabela 1).

\begin{tabular}{lcccc|}
\hline Escolas & \multicolumn{1}{c}{ Série } & No de Alunos & Localidade \\
\hline APAE de Carangola & Ensino para crianças especiais & 26 & Carangola/MG \\
\hline Educandário São José & $6^{\circ}$ Ano ensino Fundamental & 26 & Porciúncula/RJ \\
\hline Educandário São José & $7^{\circ}$ Ano ensino Fundamental & 26 & Porciúncula/RJ \\
\hline Educandário São José & $8^{\circ}$ Ano ensino Fundamental & 24 & Porciúncula/RJ \\
\hline Educandário São José & $9^{\circ}$ Ano ensino Fundamental & 27 & Porciúncula/RJ \\
\hline E.E. Melo Viana & Turma de tempo integral & 70 & Carangola/MG \\
\hline E.E. Melo Viana & $3^{\circ}$ Ano ensino Fundamental & 30 & Carangola/MG \\
\hline E.E. Melo Viana & $2^{\circ}$ Ano ensino Fundamental & 27 & Carangola/MG \\
\hline E. E. Dr Jonas de Faria Castro & $3^{\circ}$ Ano ensino Fundamental & 27 & Carangola/MG \\
\hline E. E. Dr Jonas de Faria Castro & $2^{\circ}$ Ano ensino Fundamental & 28 & Carangola/MG \\
\hline
\end{tabular}




\begin{tabular}{|lcccc}
\hline E.E. João Belo de Oliveira & $7^{\circ}$ Ano ensino Fundamental & 50 & Carangola/MG \\
\hline E.E. Emília Esteves Marques & $8^{\circ}$ Ano ensino Fundamental & 55 & Carangola/MG \\
\hline Escola Oficina do Saber & $1^{\circ}$ Ano ensino Fundamental & 23 & Carangola/MG \\
\hline Escola Oficina do Saber & $2^{\circ}$ Ano ensino Fundamental & 25 & Carangola/Mg \\
\hline Escola Oficina do Saber & $3^{\circ}$ Ano ensino Fundamental & 21 & Carangola/MG \\
\hline Escola Oficina do Saber & $4^{\circ}$ Ano ensino Fundamental & 25 & Carangola/MG \\
\hline Escola Oficina do Saber & $5^{\circ}$ Ano ensino Fundamental & 26 & Carangola/MG \\
\hline E.E. Augusto Amarante & Turma de tempo integral & 50 & Carangola/MG \\
\hline E. M. Santa Luzia & $6^{\circ}$ Ano ensino Fundamental & 20 & Carangola/MG \\
\hline E. M. Santa Luzia & $7^{\circ}$ Ano ensino Fundamental & 15 & Carangola/MG \\
\hline E. M. Santa Luzia & $8^{\circ}$ Ano ensino Fundamental & 17 & Carangola/MG \\
\hline E. M. Santa Luzia & $9^{\circ}$ Ano ensino Fundamental & 21 & Carangola/MG \\
\hline E. E. Emília Esteves Marques & $1^{\circ}$ Ano ensino Médio & 20 & Carangola/MG \\
\hline Total Esteves Marques & $2^{\circ}$ Ano ensino Médio & 22 & Carangola/MG \\
\hline
\end{tabular}

De posse do conteúdo que os professores ministravam em sala, os estudantes de licenciatura em Ciências Biológicas buscaram novas metodologias de ensino, utilizando o HUEMG, que facilitassem o aprendizado dos alunos envolvidos no projeto. Dessa forma, os graduandos em Ciências Biológicas, participantes do trabalho, tiveram oportunidade de exercer a iniciação à docência. Como parte das atividades propostas pelo projeto, foram analisados os livros didáticos adotados pelos professores, a fim de se construir práticas de ensino em botânica em forma de trabalhos multidisciplinares em consonância com o conteúdo lecionado em sala.

Além disso, ministraram-se aulas expositivas, com auxílio de slides, em salas, com equipamentos de alta tecnologia como lousa inteligente; em laboratórios de Biologia, ao ar livre, a fim de despertar nos alunos o interesse pela preservação do meio ambiente no qual estão inseridos, sobretudo da importância do HUEMG. As sequências didáticas ministradas tiveram diversos temas: Mata Atlântica, habitats e adaptações morfológicas das plantas, a relevância das coleções botânicas, o uso de plantas medicinais, construindo uma horta de plantas medicinais, vídeo educativo falando sobre a Mata Atlântica e aula prática em laboratório a respeito da célula vegetal. 


\section{RESULTADOS}

Durante o ano letivo de 2016, contou-se com a participação de nove escolas, sendo oito do Município de Carangola-MG e uma do município de Porciúncula-RJ. Dessas, duas escolas pertencem à rede privada de ensino e seis à rede pública, sendo cinco delas estaduais e uma municipal, abrangendo um total de 701 alunos, dos ensinos fundamentais (73\%), médio (42\%) e educação especial (4\%). Além disso, nesse período, participaram do trabalho oito professores de Ciências, um professor de Biologia e nove professores da área da Pedagogia (Tabela 1).

É notório que a inserção das coleções biológicas, no contexto didático, tem contribuído muito para a divulgação científica e para o ensino de biologia e áreas afins. Nesse sentido, alguns trabalhos envolvendo visitas às coleções científicas recebem visitantes, variando a quantidade de acordo com os objetivos de cada estudo. Em trabalho realizado por Faria e Souza (2015) em um Museu de Zoologia, foi registrado um total de 133 alunos visitantes de ensino fundamental dentre escolas públicas. Faria e Leodoro (2016) receberam 389 visitantes na coleção zoológica, enquanto Dias e coloboradores (2009) receberam 70 alunos no Jardim Botânico de Curitiba, em um trabalho similar. Lima \& Barbosa (2016), em trabalho realizado no Museu de Zoologia, calcularam no ano de 2015 um total de 1.083 visitantes, dentre pessoas físicas e grupos escolares. Assim, fica evidente a demanda existente e o interesse dos visitantes às coleções, o que pode ser muito importante do ponto de vista didático. No entanto, esse serviço nem sempre está disponível nas coleções biológicas, por várias razões como, por exemplo, a falta de recursos financeiros e humanos, já que as coleções são tradicionalmente de cunho científico.

O interesse dos professores em participar do trabalho foi importante, uma vez que a maioria deles não possuia um grande conhecimento sobre como dinamizar o conteúdo botânico. Dentre outros fatores importantes que podem aumentar essa problemática, citam-se a falta de estrutura das escolas e a ausência de recursos (humano e financeiro). Como acontece nas escolas públicas, há um elevado número de alunos por turma, ausência de laboratórios e o tempo exíguo que os professores têm para preparar e ministrar a disciplina de ciências. Estes pontos, somados à dificuldade de os professores realizarem aulas práticas, resulta na carência do conteúdo de botânica que estes alunos apresentavam (SILVA et al., 2014).

Em trabalho realizado por Santos et al. (2008) foi enfatizado que "o Ensino de Botânica tem sido de maneira geral, negligenciado nos diferentes anos da Educação Básica"; o mesmo tem sido ministrado de maneira muito teórica, tanta teoria pode ser a consequência da enorme dificuldade que os professores apresentam de expor e explorar o conteúdo de maneira prática e contextualizada. Santos et al. (2010) relataram que, dentre os conteúdos da disciplina de Ciências e Biologia, a botânica é um dos conteúdos em que os professores apresentavam maior dificuldade para envolver os alunos.

Outra dificuldade apontada pelos professores do ensino fundamental I diz respeito à nomenclatura usada no conteúdo botânico. Essas terminologias dificul- 
tam a sua utilização pelo professor e para os alunos absorverem o que thes é transmitido (SILVA et al., 2014), talvez isso aconteça pela forma com que o conteúdo é passado para os alunos e também pela falta de atualização do professor em relação ao conteúdo botânico.

Porém, o desinteresse sobre o conteúdo de botânica não é somente em relação aos alunos mas também se dá por parte dos professores, ao não buscarem novas metodologias para o ensino. Macias (2011), ao questionar docentes de Ciências e Biologia em Pelotas-RS, sobre as áreas de maior interesse da disciplina de Ciências e Biologia, dentre elas Genética, Botânica, Zoologia, Saúde Pública e Histologia, constatou que Genética ficou em primeiro lugar na preferência dos discentes e o conteúdo Botânica por último.

Visando contribuir para promover o interesse para esta área da ciência foram iniciadas as visitas à Unidade de Carangola, pois todos os alunos conheceram o CEBIO, o Herbário e o seu funcionamento. Como forma de divulgação da coleção científica de plantas da UEMG Carangola, e para que eles tivessem acesso a UEMG, foi ministrado o conteúdo teórico em salas com equipamento de multimídia na sala da UAITEC e depois e a coleção do HUEMG (Figura 1).
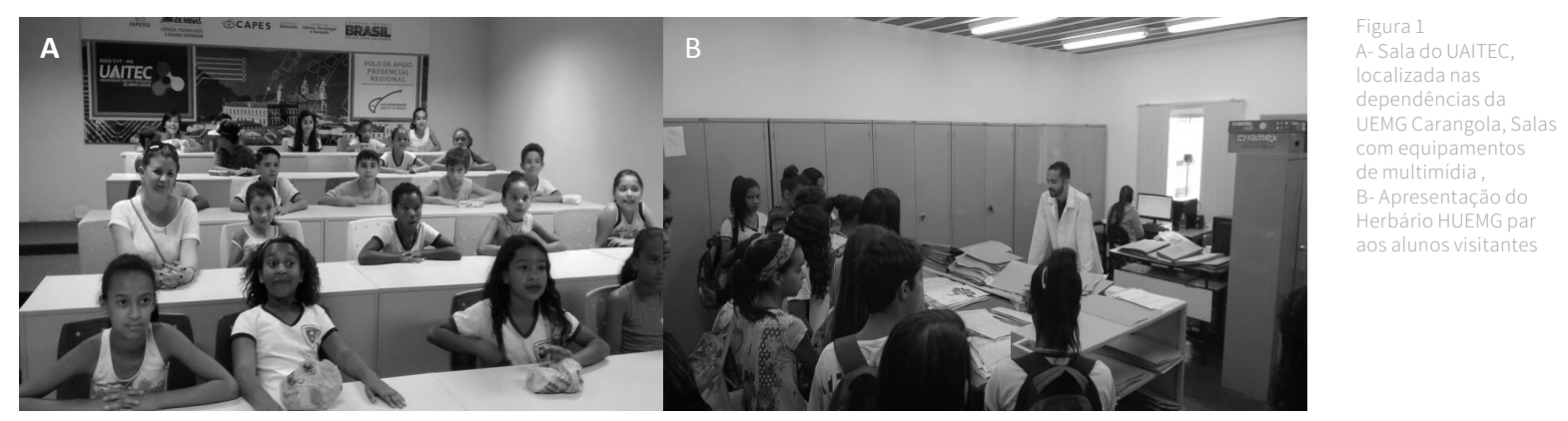

Ao longo das visitas técnicas ao Herbário da HUEMG, foi possível apresentar in loco a importância das coleções botânicas para o ensino e a conservação da biodiversidade florística regional. As visitas tiveram como foco principal a compreensão das coleções científicas, como ferramenta para o desenvolvimento de pesquisas, nas diversas áreas da ciência e sua importância para ensino da Botânica (NUNES \& ALVES, 2016).

As aulas teóricas tiveram diversos assuntos abordados, entre eles, conceitos a respeito da relevância das coleções botânicas para estudos da biodiversidade, o uso de plantas medicinais, vegetação da Mata Atlântica, conservação das espécies e inserção da educação ambiental no cotidiano, adaptações morfológicas, uso e importância econômica. Além disso, outros assuntos atuais foram inseridos de maneira a contextualizar com situações do cotidiano do aluno, por exemplo, a presença de plantas que podem servir de criadouros de mosquitos transmissores de doenças. 
Sabe-se que aulas diferenciadas ao ar livre fazem com que os alunos valorizem os conteúdos ministrados e se envolvam mais com os temas abordados (RISSI \& CAVASSAN, 2013). E, ainda, que os museus e centros de ciências estimulam a curiosidade dos visitantes. Esses espaços oferecem a oportunidade de suprir, ao menos em parte, algumas das carências da escola como a falta de laboratórios, recursos audiovisuais, entre outros, conhecidos por estimular o aprendizado. 0 Herbário pode ser utilizado com fins didáticos para o aprimoramento ao ensino de Ciências e Biologia nas escolas, promovendo assim a popularização e democratização do saber científico (OLIVEIRA et al. 2014; NUNES \& ALVES, 2016).

O tema Plantas Medicinais, foi trabalhado em aulas teóricas e práticas, em que se abordou o conteúdo de diversidade de plantas medicinais com enfoque nas plantas medicinais na região de Carangola, de acordo com Nunes \& Lanes (2016). 0 desenvolvimento dessa temática foi de extremo interesse dos professores, contribuindo para que os alunos tivessem um maior interesse pelo conteúdo. Primeiramente foi ministrada a aula teórica, em seguida os alunos visitaram a coleção para conhecer alguns exemplares exsicatados de plantas medicinais que estão depositadas no HUEMG segundo Oliveira et al., (2014). Outra prática ministrada, com sucesso, foi a construção de uma horta vertical. Para tal, utilizou-se como canteiros garrafas pet para o plantio de ervas medicinais. Aqui se destaca o uso da garrafa pet que, normalmente, é um material descartado no meio ambiente. O fato é que as atividades práticas possibilitam aos alunos a interação com as plantas em um todo, o que oportuniza a valorização desse tipo de ser vivo e a compreensão como elemento essencial para qualquer ambiente (BITENCOURT et al., 2011).

E, ainda, a construção de uma Horta Medicinal, como aula prática, pode aprimorar o desenvolvimento cognitivo, relacionando temas de ciências trabalhados em sala de aula com as atividades práticas. Inserida no ambiente escolar, esta ação pode possibilitar o desenvolvimento de diversas atividades pedagógicas em educação ambiental, unindo teoria e prática de forma contextualizada, auxiliando no processo de ensino-aprendizagem e estreitando relações através da promoção do trabalho coletivo e cooperativo, entre os agentes sociais envolvidos (SILVA \& SANTOS, 2009) (Figura 2).
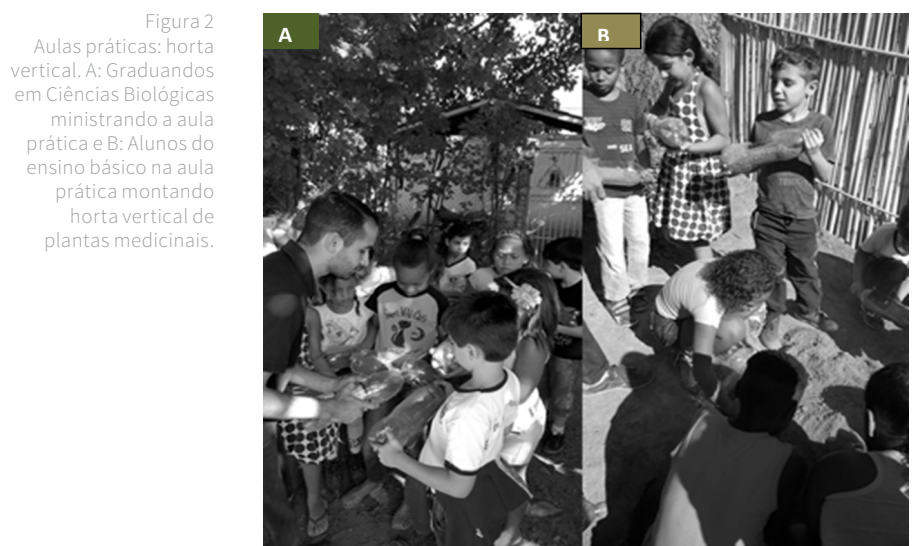
Nesse contexto, tratou-se também sobre a importância da reciclagem para a diminuição da degradação do meio ambiente.

Os alunos da APAE Carangola também participaram do estudo. Para essa aula foi preparada uma dinâmica com um vídeo educativo "Os Guardiões da Biosfera - Mata Atlântica”. Apesar das limitações, os alunos manifestaram interesse em conhecer a coleção do HUEMG, pois nunca haviam visitado uma coleção científica antes. Tal aula foi de suma importância, ao contribuir para promover a inclusão destes alunos em uma realidade com a qual eles dificilmente teriam contato em seu cotidiano.

Importante ressaltar aqui a importância de se adequar o conteúdo ao público uma vez que, para as visitas, vieram alunos das séries iniciais às finais da educação básica e alunos especiais. Essa é uma importante prática para os alunos, responsáveis em desenvolver as aulas na medida em que agem na prática da formação docente. É preciso se levar em conta que a inclusão aumenta as possibilidades dos indivíduos com algum tipo de deficiência a estabelecerem significativos laços de amizade, de se desenvolverem física e cognitivamente e de serem membros ativos na escola e na construção de conhecimentos (BERETA \& VIANA, 2014). A aula com recurso audiovisual ocorreu nas dependências do UAITEC (Figura 3).

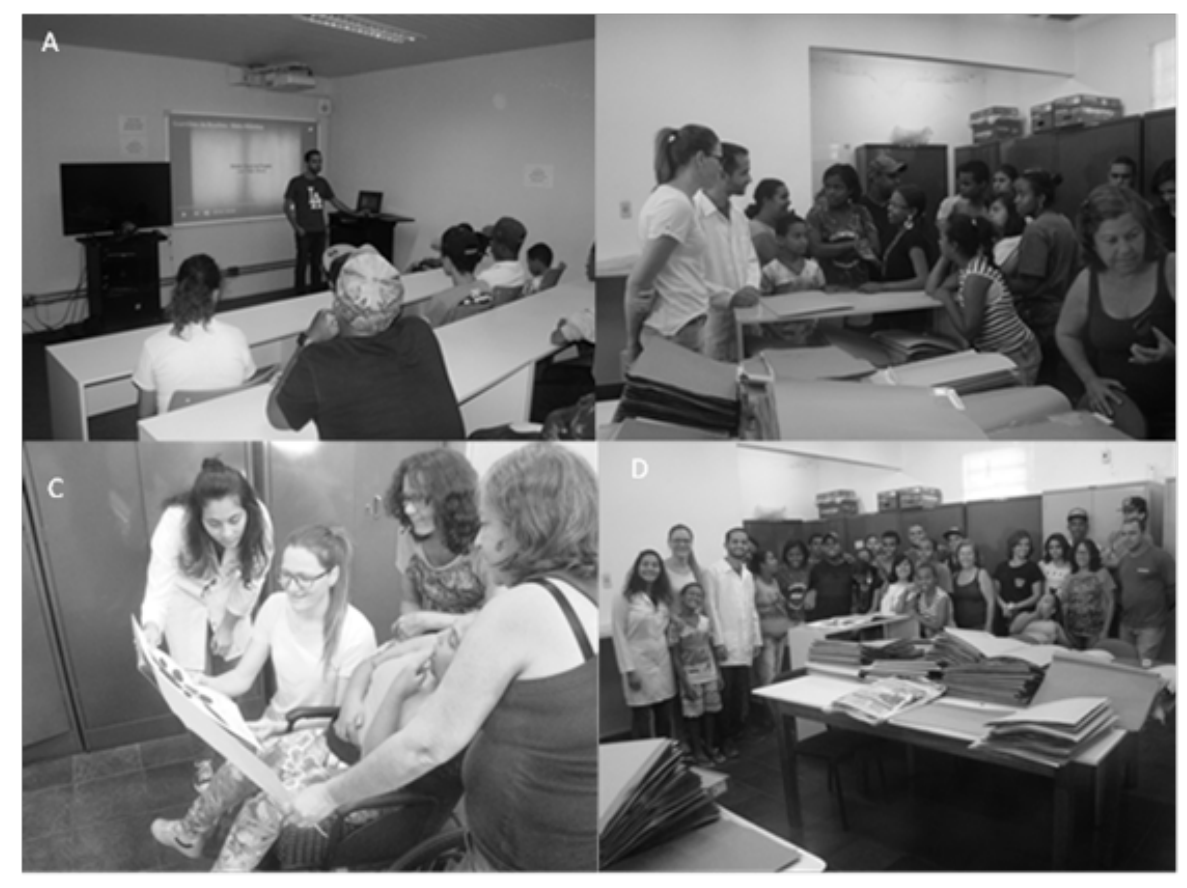

Foi notório o despertar do interesse dos alunos, quando realizadas as aulas práticas em laboratório, com o uso de microscópio, lupas e outros equipamentos (Figura 4). 


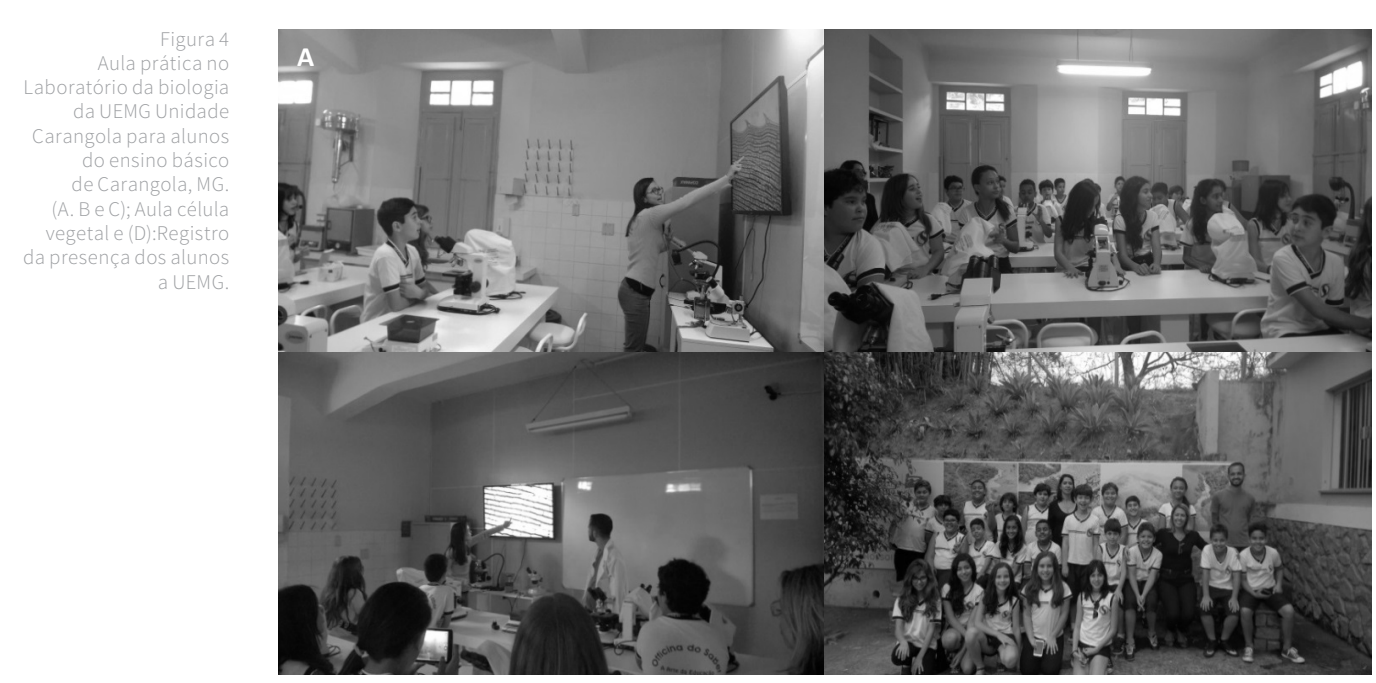

Em trabalho realizado por Krasilchik (2008) dentre as modalidades didáticas existentes, tais como aulas expositivas, demonstrações, excursões, discussões, aulas práticas e projetos, como forma de vivenciar o método científico, as aulas práticas e projetos estão entre os mais adequados. Dentre as principais funções das aulas práticas a autora cita: despertar e manter o interesse dos alunos; envolver os estudantes em investigações científicas; desenvolver a capacidade de resolver problemas; compreender conceitos básicos; e desenvolver habilidades.

Que as aulas práticas são importantes para um melhor aprendizado isso é evidente, pois são elas que fazem com que os alunos se tornem agentes atuantes, tendo nelas aulas o fator essencial para uma boa formação acadêmica. Para Amorim et al. (2012), as aulas práticas propiciam a melhoria da compreensão, a ampliação e a apropriação dos conteúdos cognitivos, o que permite a construção e a aplicação de habilidades procedimentais e atitudinais, levando o aluno a ter um pensamento mais crítico e reflexivo.

Em trabalho realizado por Pontarolo \& Tardivo (2011) no Herbário da Universidade Estadual de Ponta Grossa, as autoras afirmam que a coleção científica de plantas é um forte instrumento didático para alunos do ensino médio, fundamental e para os graduandos. Ao visitar uma coleção científica, os alunos conhecem a manutenção do local, as espécies que estão depositadas lá, e dessa forma eles passam a ter uma noção maior da importância deste espaço. Constataram ainda, neste estudo, que o herbário se faz como um ótimo instrumento pedagógico, que contribui amplamente nos ensinos de ciências e biologia no conteúdo de botânica, e desperta nos alunos o interesse para conhecer ainda mais a flora da região em que vivem. Diversos trabalhos, entre eles o de Nabozny \& Tardivo (2016) destacam que as atividades de extensão realizadas em herbários se mostram como ferramentas eficazes para o ensino do conteúdo de botânica e ressaltam que as visitas em herbários são de suma importância ao trazer a comunidade para a realidade das pesquisas, quebrando tabus existentes em torno da vida acadêmica. Já para 
botânicos mais conservadores, as coleções científicas devem ser de uso exclusivo para pesquisa e uso de especialistas, visando à preservação da coleção, conforme defendem Fonseca \& Vieira (2015). Também para Silva (2016), as coleções devem ser usadas somente para fins de pesquisa, por especialistas da área e não para visitação pública, a fim de se evitar contaminações no ambiente das coleções, dessa forma preservando o material.

Destaque aqui pode ser dado ao Herbário HUEMG, que atualmente, além de cumprir o seu papel na pesquisa acadêmica, também se conceitua como instrumento didático para os alunos graduandos em Ciências Biológicas, bem como para alunos e professores da rede de ensino básico de Carangola e região. Vale a pena ressaltar que, todas as aulas teóricas e práticas foram realizadas fora do espaço onde se encontra a coleção de plantas do HUEMG. Isso porque a coleção deve ser preservada em temperatura e umidade ideal e livre de contaminação, por se tratar de um bem público. Para isso, usamos o espaço externo na UEMG - Unidade de Carangola, como CEBio, pátio, laboratórios, salas de aula, salas de multimídias e UAITEC. Em estudo realizado, Vieira et al. (2014, constataram que o ensino de ciências em espaços de educação não formal possui grande valia.

Com a realização das montagens das sequências didáticas e, posteriormente, com as suas aplicações, deu-se um grande impulso para a iniciação à docência dos alunos das Ciências Biológicas da UEMG-Carangola envolvidos no projeto. Isso porque possibilitou aos graduandos entrarem em um ambiente escolar para ministrar as aulas teóricas e práticas, adquirindo assim experiência na docência. Observou-se que a educação não formal é um instrumento muito eficiente no tocante ao melhoramento do ensino. E, no caso do presente estudo, propiciou o despertar do interesse dos alunos pelo conteúdo da botânica tão logo ministraram as aulas.

\section{CONCLUSÕES}

O número de alunos e participantes do projeto foi satisfatório, o que demonstra a importância do trabalho como contribuição ao ensino de Botânica na educação básica. Esse interesse se explica porque a possibilidade de haver aula prática, fora da sala de aula formal, por si só já é uma situação diferente e estimulante para alunos e professores. As aulas práticas e teóricas que foram realizadas usando o HUEMG como instrumento educacional e laboratórios de biologia, em complemento ao livro didático, contribuíram em muito para melhorar a aprendizagem dos alunos a respeito da botânica, nas disciplinas de Ciências e Biologia. As espécies representantes da flora local, utilizadas na demonstração, ao serem conhecidas pelos alunos despertam o interesse e a curiosidade. Isso os leva a indagações e comparações, integrando-os à região em que vivem por meio desse conhecimento, contribuindo assim para o exercício de responsabilidade social em relação ao meio ambiente.

Pelas atividades desenvolvidas pelo projeto e os resultados observados, 
concluiu-se que a iniciação à docência aos graduandos em biologia foi de grande importância e relevância, na medida em que oportunizou a inserção no âmbito escolar, em contato com professores e alunos na prática, em um processo de elaboração de aulas não formais de botânica para os alunos da educação básica de Carangola e região.

\section{REFERÊNCIAS}

[1] AMORIM, A.C.F., SILVA, L.A., MONTEIRO, D.X., ROCHA, M.A., SANTOS, A.M.M. A atividade prática como uma importante ferramenta metodológica no ensino da botânica. $63^{\circ}$ Congresso Nacional de Botânica- Botânica frente as mudanças globais. Joinville-Santa Catarina 2012.

[2] ARAúJo, M. S.; MIGUeL, J. R. Herbário Didático no ensino da Botânica. In: I Encontro de Pesquisa em Ensino de Ciências e Matemática: questões atuais, 2013.

[3] BERETA, M.S., VIANA, P. B. D. M. Os benefícios da inclusão de alunos com deficiência em escolas regulares. Revista Pós-graduação: Desafios Contemporâneos, v.1, n. 1, jun./2014.

[4] BITENCOURT, I. M.; MACEDO, G. E. L.; SOUZA, M. L.; SANTOS, M. C.; SOUSA, G. P.; OLIVEIRA, D. B. C. As plantas na percepção de estudantes do ensino fundamental no município de Jequié - Ba. VIII Encontro Nacional de Pesquisa, Campinas, Brasil. 2011

[5] DIAS, J. M. D. C., SCHWARZ, E. D. A. VIEIRA, E. D. R. A botânica além da sala de aula. 2009. Disponível em: < http://www.diaadiaeducacao.pr.gov.br/portals/pde/arquivos/893-4.pdf > acesso em: set. 2014

[6] FARIA, M. B.; LEODORO, I. L. Cultural Events as Tools for Disseminating of the Zoology Museum of the University of Minas Gerais States, Brazil. Palgo Journal of Education Research, v. 4, p. 189, 2016

[7] FARIA, M. B.; SOUZA, G. C., Popularização da ciência através do Museu de Zoologia Newton Baião de Azevedo: conservação da fauna. Revista Científica Semana Acadêmica, v. 000067, p. 1, 2015.

[8] Fonseca, R. S., Vieira, M. F. Coleções botânicas com enfoque em herbário, - Viçosa, MG : Ed. UFV, 2015.

[9] Krasilchik, M. Prática de Ensino de Biologia. São Paulo EDUSP, 2008.

[10] Lima, J. F. D. S., Barbosa, M. V. M. Atuações educativas do Museu de Zoologia "José Hidasi" da Unitins p;ra com as Instituições de Ensino e Comunidades Tocantinenses. Revista Humanidades e Inovação, v.3, n. 1, 2016.

[11] Machado S. R., Barbosa S. B. Herbário Botucatu: Manual de procedimentos. São Paulo-SP. 2010.

[12] Macias, L. Ensino de Botânica no contexto das escolas públicas e propostas para a formação continuada dos professores. In: LUCENA, E. M. P., AMORIM, A. V. (Orgs.). $62^{\circ}$ Congresso Nacional de Botânica -Botânica e Desenvolvimento Sustentável. Fortaleza: EdUECE, 2011.

[13] Menezes, L. C. De; Souza, V. C.; Nicomedes, M. P.; Silva, N. A.; Quirino, M. R.; Oliveira, A. G.; Andrade, R. R.; Santos, C. Anais do XI Encontro de Iniciação à Docência. In: Iniciativas para o aprendizado de botânica no ensino médio. UFPB. 2009.

[14] Nabozny, R., Tardivo, R. C. Herbário Da Universidade Estadual De Ponta Grossa (HUPG): Experiências e trabalhos desenvolvidos. In: 140 CONEX-Conversando Sobre Extensão- Universidade de Ponta Grossa- PR, 2016.

[15] Nunes, J. A., Alves, N. B. Herbário HUEMG como ferramenta para educação e conservação da biodiversidade. Revista Científica Semana Acadêmica, v. 1, p. 1-16, 2016.

[16] Nunes, J. A., Lanes, G. S. D. Uso de Plantas Medicinais no Município de Carangola-MG. In: Otávio Luiz Machado. (Org.). Universidade de Idéias. 1 ed. Frutal: Editora Prospectiva; v. 1, p. 285-309, 2016.

[17] Oliveira, E. E., Toledo, T. D. F., Da Silva, D. F. M. Nunes, J. A., Levantamento etnobotânico das espé- 
cies medicinais do herbário da Universidade do Estado de Minas Gerais - HUEMG. In: XI Encontro Internacional de Iniciação Científica da FAMINAS, 2014, Muriaé.

[18] Oliveira, M. L, Antunes, A. M., Rocha, T. L., Teixeira, S. M. Educação inclusiva e a formação de professores de ciências: o papel das universidades federais na capacitação dos futuros educadores. Revista Ensaio, Belo Horizonte; vol 13, n. 3, p.99-117, 2011.

[19] Pessin, L. R., Nascimento, M. T. A importância das aulas práticas no ensino de botânica, a partir do processo de ensino e aprendizagem em aulas e atividades teórico práticas. $15^{\circ}$ Encontro de IC da UENF;70 Circuito de IC da IFF; 3 a Jornada de IC da UFF. II Congresso Fluminense de Iniciação Científica e Tecnológica, 2010.

[20] Pontarolo, A. R., Tardivo, R. C. As coleções biológicas como instrumento de educação e conservação da biodiversidade do planeta. $9^{\circ}$ Conex- Encontro Conversando sobre Extensão no UEPG." Extensão e formação Universitária: Repensando o Currículo", Universidade Estadual de Ponta Grossa- Resumo Expandido, 2011.

[21] Possobom, C. Atividades práticas no Ensino de Biologia e de Ciências: Relato de uma experiência. Ciência e Educação, p. 113-123, 2002.

[22] Rissi, M.n., Cavassan, 0. Uma proposta de material didático baseado nas espécies de Vochysiaceae existentes em uma trilha no cerrado de Bauru - SP. Biota Neotropical, v. 13, n.1: p.27-41, 2013

[23] Rockenbach, M. E., Oliveira, J. H. F., Pesamosca, A. M.; Castro, P. E. E., Macias, L. Não se gosta do que conhece? A visão de alunos sobre a botânica. In: XXI Congresso de Iniciação Cientifica, $4^{\circ}$ Mostra Cientifica Universidade Federal de Pelotas, 2012.

[24] Santos, D. Y. A. C., Chow F., Furlan, C. M. (Orgs.). Ensino de Botânica - Curso para atualização de professores de Educação Básica: A Botânica no cotidiano. São Paulo. 2008.

[25] Santos, F. S. A, Botânica no Ensino Médio: Será que é preciso apenas memorizar nomes de plantas? In C. C. Silva (Org.). Estudos de história e filosofia das ciências: Subsídios para aplicação no ensino (p. 223-243). São Paulo: Editora Livraria da Física, 2006.

[26] Santos, S. P., Rodrigues, F. F. S., Pereira, B. B. O ensino de Botânica e as práticas escolares: Diálogos com a educação de jovens e adultos. In: II Seminário de Pesquisa do NUPEPE. Uberlândia, 2010.

[27] Silva, L. A. M., Manual do usuário do Herbário UESC; Universidade Estadual de Santa Cruz, Ilhéus, BA, 2016.

[28] Silva, M. J., Sampaio, S. M.v., Nunes, J. V. C. O que dizem os professores das escolas públicas de Maceió sobre o ensino de botânica?. V Enebio e II Erebio Regional 1- Revista da SBEnBIO, n. 7, 2014.

[29] Silva M., Santos, M. A. A. A horta escolar na educação ambiental e alimentar: experiência do Projeto Horta Viva nas escolas municipais de Florianópolis. Extenso: Revista Eletrônica de Extensão, v. 5, n. 6, 2009.

[30] Vieira, G. Q., Pereira, L. P., Matos, W. R. Avaliação de espaços não formais de educação para o ensino de Ciências: Estudo de caso do museu Ciência e Vida, Duque de Caxias, RJ. Almanaque multidisciplinar de pesquisa. ANO I-v. 1, n. 2- Artigo- Universidade Unigranrio, 2014.

\section{AGRADECIMENTOS}

Os autores agradecem ao Programa de Apoio a Projetos de Extensão - PAEX da Universidade do Estado de Minas Gerais pela bolsa de Iniciação Científica.

Ao Herbário da Universidade do Estado de Minas Gerais - HUEMG. 